proximal to the pylorus, he should later carry out a further operation for the removal of the pylorus and the residual portion of the antrum. The Billroth I method of anastomosis between the stump of the stomach and duodenum also appears to be inadvisable. This technique is excellent for gastric lesions, but appears to carry an increased risk of stomal ulcer if it is used for duodenal cases, even though the ulcer has been completely removed. The addition of an enteroanastomosis between the jejunal loops at the stoma is as unwise in partial gastrectomy as it is with gastro-enterostomy. It should never be necessary. Although the bulk of the acid-secreting mucosa may have been removed, it is asking too much of the resistance of the jejunum to divert the alkaline juices beyond the stoma altogether.

The basic problem remains with us. We understand very little of the essential defence mechanism of the mucosa against erosion. We know that acid peptic activity is the essential factor in the eroding force and that the operation of partial gastrectomy properly performed will, by reducing the scale of the attack, prevent the formation of new ulceration in most cases. This operation, with or without modifications, entails disabilities which in the present state of our knowledge we must accept as a necessary and worthwhile sacrifice to secure freedom from further ulceration. The disquieting reflection, however, is that this sacrifice is really necessary in only a third of the patients, but that all are called upon to make it, because there is yet no practicable preoperative means of selection of cases into those prone to anastomotic ulcer and those not so prone.

\title{
THE TREATMENT OF PYLORIC STENOSIS IN PEPTIC ULCERATIONS
}

\author{
By F. M. Parsons, B.Sc., M.B., Ch.B (Leeds)* \\ Research Fellow iu Urology in the University of Leeds \\ and G. Watkinson, M.D., M.R.C.P. \\ Lecturer in Medicine in the University of Leeds
}

A combination of spasm, oedema and cicatrical deformity in relation to an ulcer near the pyloric ring produces a temporary or permanent retention of gastric contents accompanied by the clinical syndrome of loss of weight, vomiting and dehydration known as pyloric stenosis. The frequent failure of antispasmodic drugs to relieve the condition is in part due to inadequate therapy but is also due to the presence of oedema and scarring.

\section{Physiological Effects}

Obstruction at the pyloric ring leads to increasing retention of gastric contents, gastritis and dilatation of the stomach which eventually leads to vomiting. The reduction in absorption of food causes starvation but it is the extrarenal loss of water, chloride, sodium and potassium, secreted by the gastric mucosa and then vomited, which is

*Aided by grants from the University of Leeds; the Yorkshire Council of the British Empire Cancer Campaign; the Board of Governors, United Leeds Hospitals; and the Leeds Regional Hospital Board. more serious and lethal. As a result of the gastritis there is an increased excretion of gastric mucus which has a high concentration of sodium. This loss of sodium, which leads to a total body deficit, largely determines the extent of the dehydration present. The chloride loss, from the gastric juice, is still, however, in excess of that of the sodium (at least 50 per cent., Gamble, I950) so that an alkalosis results which may be severe enough to cause latent or manifest tetany (Fig. I). Whether this tetany is due to a decrease in ionizable calcium in the extracellular fluid or to other causes has not been clarified. Of equal, if not more, importance is the development of severe renal impairment which occurs in alkalosis. Nazzari (1904) observed calcareous infiltration in the renal tubules in two patients who died as a result of pyloric obstruction. Brown, Eusterman, Hartman and Rowntree (1923) observed at autopsy calcification in the proximal tubules in four patients who died with pyloric stenosis. They tied the pylorus of cats and within 48 hours of 


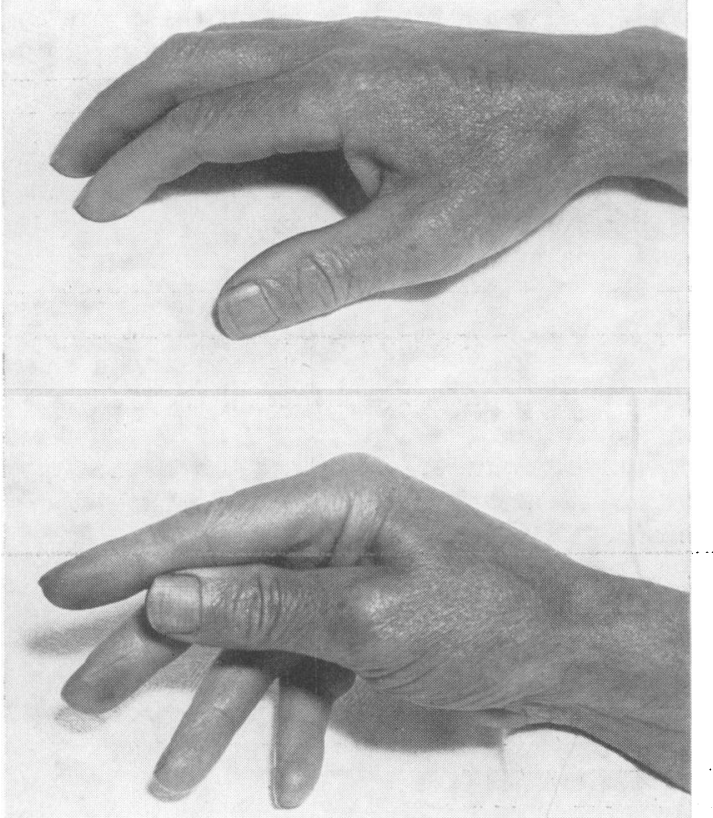

FIG. I.-Latent tetany in a patient with pyloric stenosis. (Upper) before and (lower) after occlusion of the blood supply.

operation observed degeneration and calcification of the tubules. These findings were confirmed by Pyrah (1949) and similar results have been obtained in the dog (Pyrah and Bonser), calcification occurring in the cells of the renal cortex and in the lumina of the proximal tubules. Cooke (1933) reported six cases of pyloric stenosis and at autopsy renal calcification, restricted mainly to the cortical area, was found in each case. Pyrah (1949) reported three similar cases and in addition observed calcareous debris in the lumina of the tubules. Fig. 2 is an example of this type of renal calcification. This renal calcification and tubular degeneration results in severe renal impairment which is frequently intensified by the pre-renal factors of dehydration and hypochloraemia. The urine in early cases is alkaline but when sodium and potassium deficiencies develop it becomes acid (Kennedy, Winkley and Dunning, 1949).

\section{Clinical Assessment of the Patient}

The history associated with benign pyloric obstruction is usually long; a preceding ulcer dyspepsia has often been present for many years but the commencement of vomiting is usually fairly recent. The volume and frequency of vomiting, in conjunction with the quantity of fluid

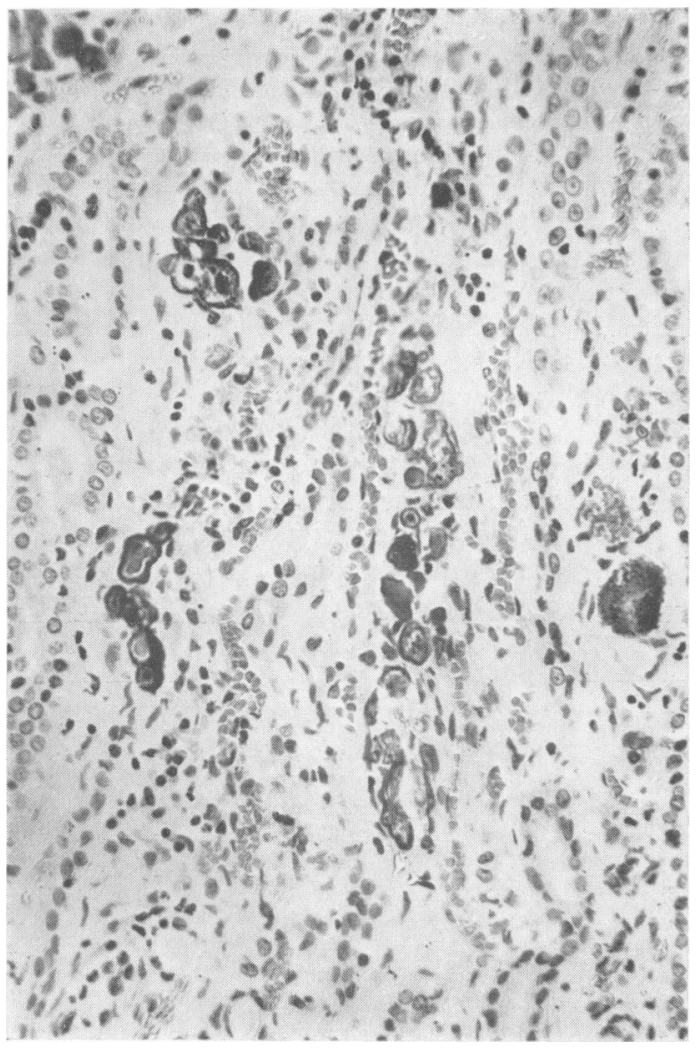

FIG. 2.-Microphotograph of kidney showing calcareous deposits, from a patient who died with pyloric stenosis.

drunk, is often a useful guide to the severity of the condition as is the degree of weight lost, if known. Symptoms of weakness, drowsiness, muscle cramps and tetany are suggestive of severe biochemical abnormalities. In eight of our recent cases one half have had mental confusion as a prominent feature-indeed one was referred initially to a neurologist and a second to a psychiatrist.

Clinical examination usually reveals local evidence of gastric dilatation in the form of a succussion splash but visible peristalsis is more rarely observed. The remainder of the clinical signs are secondary to the obstruction. Besides evidence of loss of weight, dehydration is almost invariably present in the severe case, the skin being dry and inelastic and the tongue dry, wrinkled and coated. Difficulty in articulation may be due more to the severe dehydration than to nervous dysfunction developing as a result of biochemical imbalance. In severe cases we have observed deep pitting 'oedema' (Fig. 3) even in the presence of manifest clinical evidence of severe dehydration. 


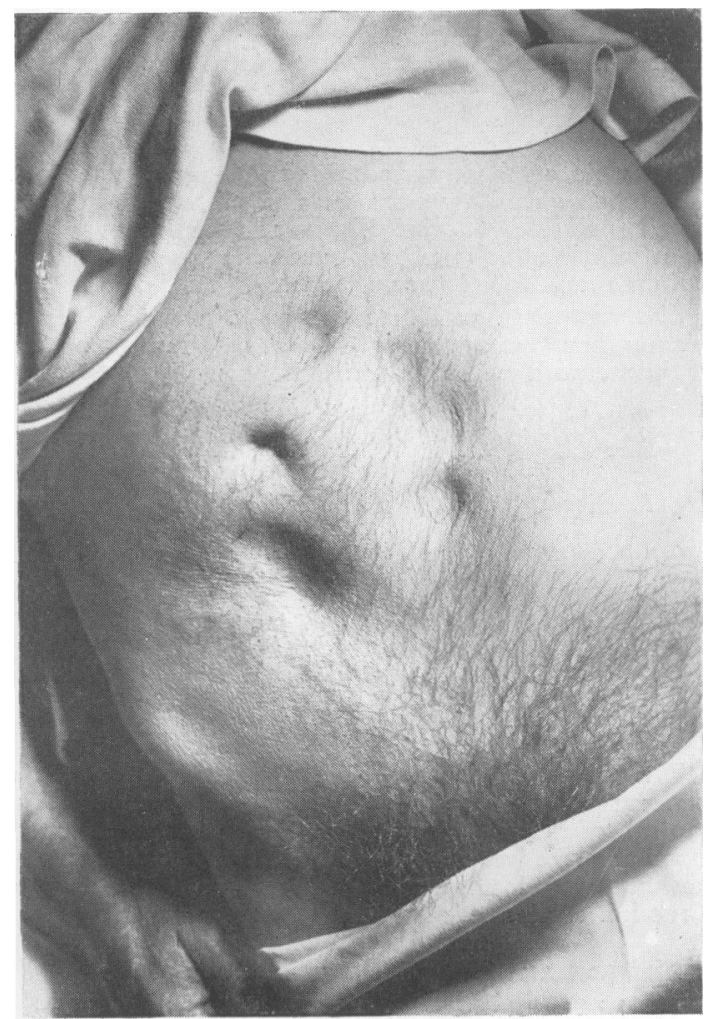

FIG. 3.- 'Finger-printing' of the abdominal wall in a severe case of pyloric stenosis (obtained by pressing the tips of left fingers and thumb into the abdominal wall for 15 secs.).

Whether this is due to intracellular or hydrostatic changes, avitaminosis or other causes has not been ascertained but it has been observed in many other cases exhibiting dehydration and low osmotic pressures of the extracellular fluid. Many of the symptoms of biochemical imbalance, for example anorexia and vomiting, are masked by the primary pathology of pyloric obstruction.

Serious cases of pyloric stenosis can only satisfactorily be treated where full laboratory facilities are available. It is advisable to estimate the plasma levels of chloride, sodium, potassium, carbon dioxide combining power, urea and proteins to make an accurate assessment of the state of the internal environment. Additional information of the body potassium may be obtained by electrocardiography for normal serum levels have been reported in the presence of frank deficiency (Hawkins, Hardy and Sampson, 195I). The severity of the dehydration is best estimated clinically for no reliable chemical test suitable for routine investigation is available; certainly the plasma protein and haematocrit levels are unreliable as these values are so often subnormal in pyloric stenosis reflecting only the malnutrition of the patient. A high blood urea level may be indicative of dehydration but may also be partly due to irreversible renal damage (Fig. 2).

Examination of the urine is essential. The 24 hour volume, its specific gravity, chloride content and $\mathrm{pH}$ are valuable estimations as a guide to therapy. In the more severe forms of pyloric stenosis a small volume of acid urine with a low chloride content is found frequently. A progress chart of the patient's intake of water, electrolytes and food should be kept together with one of the urine volume and fluid loss from vomiting and gastric aspiration, making full allowance for the insensible loss of approximately I $1 . / 24$-hours occurring from the lungs and skin.

\section{Principles of Treatment}

Treatment should be planned along the following lines:

I. To correct the fluid depletion and the electrolyte abnormalities which have developed.

2. To empty the stomach daily thereby preventing overdistension and also to reduce the degree of gastritis present. This will allow the muscle tone of the stomach to improve and may reduce spasm and oedema at the pyloric ring. It must be realized, however, that gastric aspiration removes vital inorganic chemicals from the body (particularly chloride) and these must be replaced by routes other than oral.

3. Whilst the electrolyte correction is proceeding, antispasmodic drugs and medical treatment may be given in the hope that spasm in relation to the ulcer will be overcome and a temporary obstruction relieved.

4. If medical treatment is not successful, surgical relief of the obstruction must be undertaken after the patient has been suitably prepared. If, on the other hand, the obstruction is relieved during medical therapy, the nutritional state should be improved and then the advisability of elective surgery can carefully be considered.

\section{Management of the Early Case}

On admission, the diagnosis should be confirmed by the demonstration of an excess of gastric contents by passing an oesophageal tube and emptying the stomach with a Senoran's evacuator. This procedure is more effective and less laborious than the use of a Ryle's tube and syringe and is facilitated by local anaesthesia of the throat with 2 per cent. anethaine. Fluid must be given, by routes other than oral, to correct the dehydration resulting from vomiting or gastric aspiration and loss from the skin, lungs and kidneys. Care must be exercised to avoid administering fluid in excess 
of requirements as temporary renal impairment may cause water retention and oedema, a condition induced in one of our cases but, fortunately, renal function recovered rapidly and no harm resulted.

Correction of the electrolyte abnormalities should be done as quickly as possible using the intravenous route. A chloride deficit may be corrected by administering normal physiological saline; the clinical rule suggested by Bartlett, Bingham and Pederson (1938) is helpful in this respect. For each $100 \mathrm{mg}$. per cent. (17 mEq./1.) that the plasma chlorides need to be raised to reach the normal $(585 \mathrm{mg}$. per cent. as $\mathrm{NaCl}$ or 100 $\mathrm{mEq}$./1.) the patient should be given $0.5 \mathrm{~g}$. $(8.5$ $\mathrm{mEq}$.) of $\mathrm{NaCl}$ per kg. of body weight. (In pyloric stenosis unlike most other types of biochemical imbalance, the plasma chloride level is of more value than that of the sodium in assessing the quantity of salt required to correct the abnormalities.)

Sodium deficiency is usually more rapidly corrected than chloride deficiency, following the administration of saline. Hypokalaemia is best corrected by intravenous administration of potassium chloride and in addition the daily basal requirement of potassium $(6 \mathrm{~g}$. of potassium chloride) should be given provided that the urinary output is adequate to deal with any excess that might be administered.

Milk feeds (5 oz. two-hourly) may be started after two days but often a milk drip is of more value in controlling pain and improving the nutrition of the patient. The routine addition of sodium citrate to milk is to be deprecated as the additional base supplied tends to increase the degree of alkalosis present. Soluble antacids should not be used as they might increase the alkalosis but full doses of tincture of belladonna, if necessary up to the limit of tolerance, should be given if any degree of spasm is suspected. Daily vitamin supplementation is administered parenterally as ascorbic acid $500 \mathrm{mg}$., nicotinamide $50 \mathrm{mg}$. and riboflavine $25 \mathrm{mg}$. Blood transfusion is frequently required to raise the haemoglobin level to normal values.

Satisfactory progress is indicated by a progressive reduction of the volume of fasting juice aspirated from the stomach and a small proportion of patients are able to take a convalescent ulcer diet after one to two weeks. Fortified milk feeds containing milk, lactose, dried milk and 'Trufood' provide a high protein diet to improve the nutrition prior to operation. In the remainder some degree of gastric retention persists and operative relief of the condition is required either by gastrectomy or gastro-enterostomy.

The importance of replacing the chloride and water aspirated from the stomach by routes other than oral is illustrated by the following case:

\section{Case I}

A female, aged 49 , was admitted with pyloric stenosi $\vec{F}$ The blood chemistry was: Plasma protein, $7.4 \mathrm{~g}$. pet cent.; chloride, $65 \mathrm{mEq} . / 1$; $\mathrm{Co}_{2}$ combining powee $39.2 \mathrm{mEq} . / 1$.; sodium, I $30 \mathrm{mEq} . / 1$; potassium, $3 \frac{3}{3}$ mEq./l.; and blood urea nitrogen, $25 \mathrm{mg}$. per cent. के

She was given an intragastric milk drip and in the evening her stomach was washed out. The chemistro of the stomach washout was as follows:

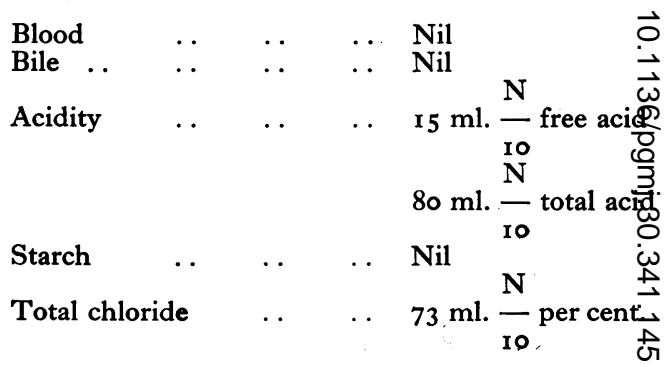

The chloride figure shows that each litre of stomac $\mathbb{B}$ washout contains as much chloride as approximately $730 \mathrm{ml}$. of normal plasma. However, as this patient's blood chloride was only $65 \mathrm{mEq}$./1., one litre of stomach washout would have contained as much chloride $\mathbf{I}, \mathbf{1 2 0} \mathrm{ml}$. of plasma.

\section{Management of the Severe Case}

In this group severe dehydration, alkalosis hypochloraemia are present, the chloride deple being grossly in excess of that of the sodium. T T a certain extent this excessive loss of chlorido over and above sodium can be made good b\% giving normal saline which has a sodium: chloride ratio of $\mathrm{I}: \mathrm{I}$, whilst that of normal plasma is $\mathrm{I} .4$ : However, it has long been recognized that saline alone will not always correct a hypochloraemi alkalosis in severe pyloric stenosis (Deeds, 1938. Jones, 1939) and some form of chloride therapy? without fixed base, is often indicated. This of paramount importance in severe cases, for an base given in excess of requirements will have to be eliminated by the kidney, already under straing and frequently showing evidence of permanent damage.

Previous experience by one of us in the manage ment of ureteric transplants led us to believe that a solution whose ionic concentration was similas to urine might be suitable for this purposes

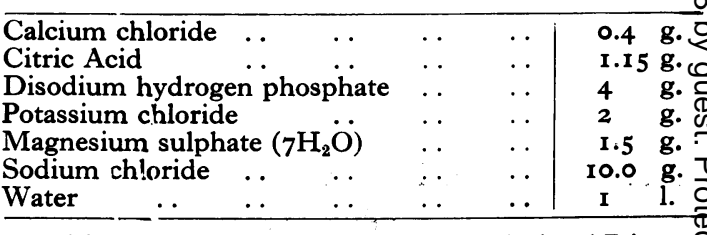

TABLE 1.-The composition of Solution ' $\mathrm{P}$.' 


\begin{tabular}{|c|c|c|c|c|c|c|c|c|}
\hline \multirow[b]{2}{*}{ Day } & \multirow{2}{*}{$\begin{array}{c}\text { Volume } \\
\mathrm{ml} \text {. }\end{array}$} & \multicolumn{2}{|c|}{ Chloride } & \multicolumn{2}{|c|}{ Sodium } & \multicolumn{2}{|c|}{ Potassium } & \multirow{2}{*}{$\begin{array}{l}\text { Urea } N_{2} \\
\text { g./24 hours }\end{array}$} \\
\hline & & $\mathrm{mEq} . / 1$. & g. $\mathrm{NaCl} / 24$ hours & $\mathrm{mEq} . / 1$. & g. $/ 2+$ hours & $\mathrm{mEq} \cdot / 1$ & g. $/ 24$ hours & \\
\hline+-5 & I 135 & 0.68 & 0.04 & 87 & 2.27 & $65 \cdot 5$ & 2.9 & $2 \cdot 7$ \\
\hline $5^{-6}$ & I 335 & 6.5 & $0.5 \mathrm{I}$ & $95 \cdot 6$ & 2.94 & 17.0 & 0.89 & 6.25 \\
\hline $6-7$ & 1485 & $34 \cdot 2$ & 2.97 & 109 & $3 \cdot 7 \mathrm{I}$ & I6. 5 & 0.96 & 8.6 \\
\hline
\end{tabular}

TABle 2.- The urine chemistry of Case 2 during treatment.

(Solution 'P,' Table I). It has been shown by Goldschmidt and Dayton (I9I9) that sulphate and phosphate enhance absorption of chloride from the intestine, and Parsons, Powell and Pyrah (1952) were able to show that differential absorption of chloride ions occurred in the large intestine. A patient treated by rectal administration of this fluid is described below:

\section{Case 2}

A male patient, aged 56 years, had had a duodenal ulcer for 12 years and for the greater part of this time symptoms had been relieved by diet and medicines. Six months before his admission he developed infrequent attacks of vomiting but later it became a daily occurrence, usually starting in the evening and lasting until 2.30 a.m. the following morning. Progressive loss of weight occurred. Examination revealed a succussion splash with slight epigastric tenderness over the duodenal area. He was treated initially with stomach washouts and milk was given by intragastric drip. Despite this treatment he continued to vomit copiously and on the fourth day he became, quite suddenly, very confused and physically violent; a few minutes later he became unconscious for half an hour but then became quite normal mentally. This cycle of events recurred four hours later.

He was seen, by one of us, for the first time between these attacks. 'There was clinical evidence of severe dehydration-indeed he had become anuric during the previous 24 hours. The blood chemistry (Fig. 4, Day 3) revealed a severe hypochloraemia, alkalosis, low values for plasma sodium and potassium and a relatively high plasma protein.

In view of the persistent vomiting, the stomach was kept empty by gastric suction and oral administration of food and fluid withheld. Intravenous therapy was given as shown in Fig. 4 , and 21 . of Solution ' $P$ ' were given by proctolysis. The next day he was mentally quite alert and the dehydration was less marked, I.4 l. of fluid being aspirated from his stomach. The blood chemistry (Fig. 4, Day 5) showed a rise in the plasma chloride, sodium and $\mathrm{CO}_{2}$ combining power, satisfactory urinary excretion returning that day. The plasma potassium level had fallen but this was not altogether surprising as the amount of potassium excreted in the urine (Table 2) was nearly as high as that administered intravenously, and dilution of the extracellular fluid was occurring. During the next 24 hours the intravenous and rectal therapy was continued (Fig. 4). The next day no clinical evidence of dehydration could be detected. The blood chemistry (Fig. 4, Day 6) was normal except for an elevated blood urea nitrogen. Investigation of the urine (Table 2) revealed a rapid rise in the chloride level during therapy but the sodium excretion remained relatively constant. The excretion of potassium fell on the fifth-sixth day and this coincided with a rise in the plasma level (Fig. 4). On the sixth day milk was given by intragastric drip but again profuse vomiting occurred.

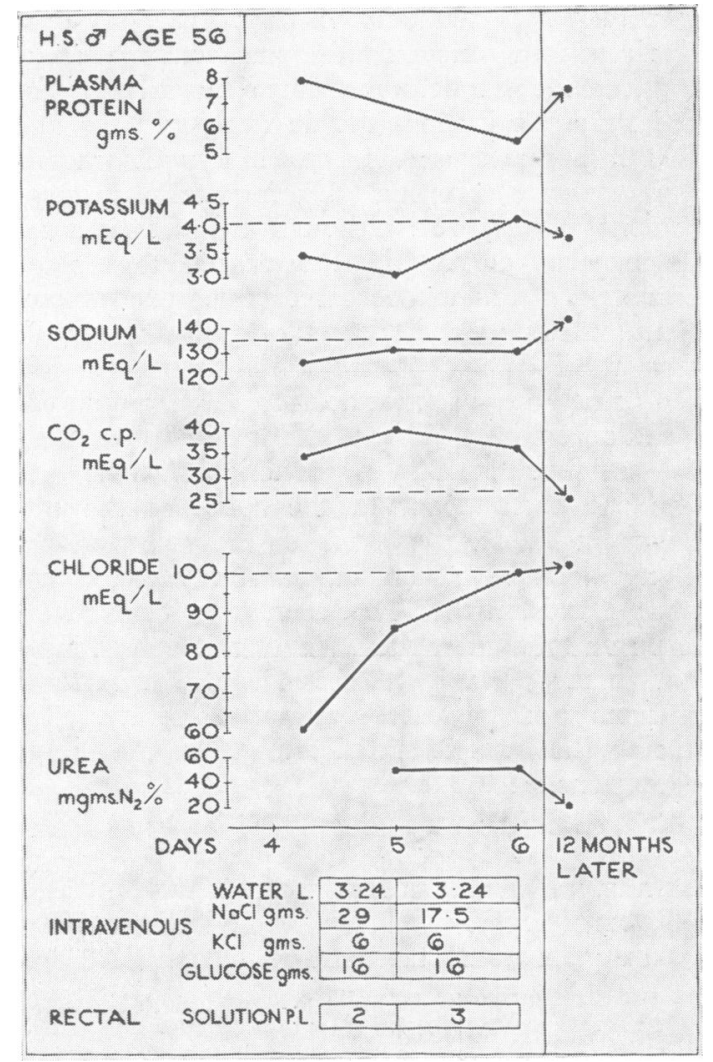

FIG. 4.-The blood chemistry and treatment of Case 2. (The horizontal dotted lines represent average normal values.)

Intravenous and rectal therapy was recommenced and on the seventh day after admission a laparotomy was performed. The duodenum and distal third of the stomach were grossly oedematous and obstructed by an active duodenal ulcer. A posterior gastro-enterostomy was performed and the patient made an uninterrupted recovery. He was reviewed one year later and was symptomless. His diet was unrestricted, he had gained in weight and he was doing a full day's work. The blood chemistry was satisfactory (Fig. 4) and the urea clearance test was 30 per cent. of average normal.

Solution ' $\mathrm{P}$ ' cannot be regarded as an ideal fluid to correct the biochemical abnormalities occurring in severe cases of pyloric stenosis, for a certain amount of sodium is absorbed by the large bowel. We believe that sodium should be 
administered by the intravenous route alone (normal physiological saline $\left(9 \mathrm{~g}\right.$. $\mathrm{NaCl} / 1$. or ${ }_{54}$ $\mathrm{mEq} . / \mathrm{l}$.) being the solution of choice) until there is no clinical evidence of dehydration and the plasma sodium level has returned to normal. The chloride depletion in excess of sodium can then be corrected rectally by sodium-free solutions, the chloride level in the plasma being used to ascertain when correction has occurred. Hydrochloric acid in concentrations sufficient materially to affect the hypochloraemia is too irritant for proctolysis; calcium chloride (22.I g./1. or 200 $\mathrm{mEq} .1 \mathrm{l}$ ) has been used in a case of hypochloraemia from excessive vomiting following a nephrectomy (Parsons, I953), but, although the chloride deficiency was corrected, it appeared that some absorption of calcium occurred which would seem highly undesirable in cases of pyloric stenosis when renal calcification is likely to occur. We then turned our attention to the use of ammonium chloride (15 g./l. or $280 \mathrm{mEq}$./1.). Absorption of these ions, even in hypertonic solutions, has been shown to occur in the colon of the dog (Boyce and Vest. 1952). Admittedly ammonium chloride can be given intravenously (McCann, 1922; Deeds, 1938). However, in an emergency, sterile ammonium chloride may not be available and, further, using the rectal route, hypertonic solutions can be used without difficulty, thus keeping the fluid administered within reasonable proportions.

The following case illustrates the use of ammonium chloride solution given by proctolysis:

\section{Case 3}

A male, aged 4I, proved, on admission, to be confused and unable to give an accurate account of past events. His relatives were also unable to contribute any useful information. He had a marked delay in cerebration, taking half to one minute to answer questions. This confused mental state led the patient's doctor to enlist the aid of a consultant neurologist. On examination there was moderate dehydration; this was in contrast to our other cases who had severe dehydration. He was vomiting (the vomitus contained blood) and an abdominal succussion splash was present. There was generalized muscular twitching and a positive Chvostek's and Trousseau's sign (Fig. I). The blood pressure was $130 / 70$, the pulse rate 48 per min. and an E.C.G. revealed a $2: 1$ heart block. The haemoglobin was 9.1 $\mathrm{g}$. per cent. and the R.B.C. 3.2 million $/ \mathrm{cmm}$.

After treatment he was able to give a 20 years' history of duodenal ulcer with typical periods of remission of symptoms. He had had numerous attacks of haematemesis and melaena and once required blood transfusion. Six months before admission he started to vomit each evening. Twice during this period he had become unconscious for a 'short period of time' and after the second attack his legs were paralyzed for a few hours.

On admission the blood chemistry (Fig. 5, Day 0-1) revealed a severe hypochloraemic alkalosis, hypokalaemia and azotaemia. For the first 36 hours of treatment 31 . of 5 per cent. glucose were given intravenously along

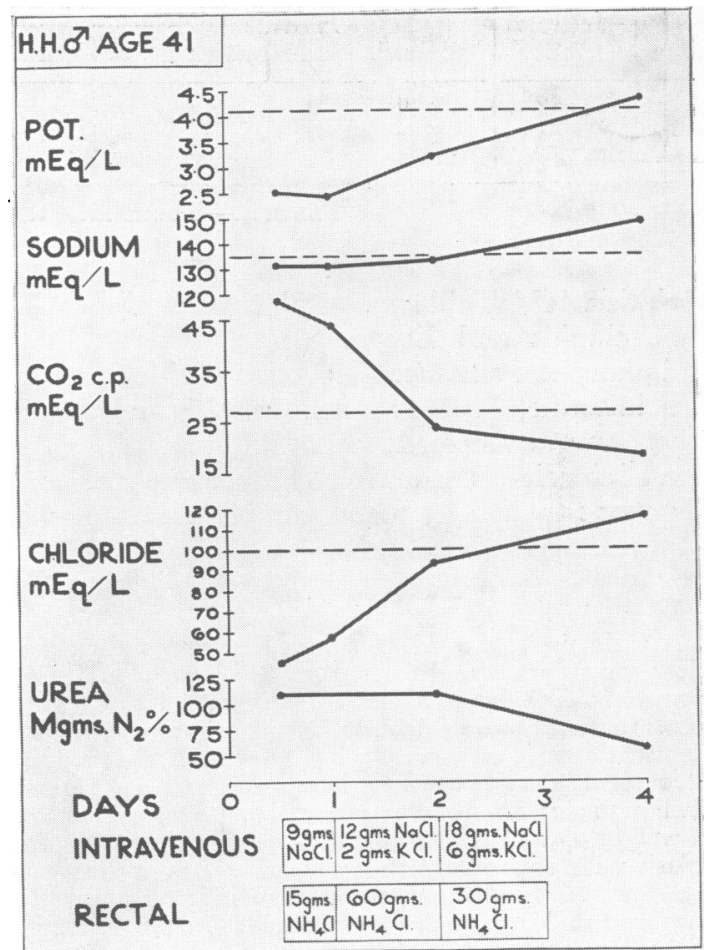

Fig. 5.-The blood chemistry and treatment of Case 3.

with inorganic chemical supplementation (Fig. 5). In order to correct the gross chloride deficit (estimated to be about $\mathrm{I}, 000 \mathrm{mEq}$.), $75 \mathrm{~g}$. of ammonium chloride $(\mathrm{I}, 400 \mathrm{mEq}$.) in 51 . of water were given by rectal drip. Not all the ammonium chloride was retained owing to rectal incontinence, but sufficient was absorbed almost to correct the chloride deficit. As the patient had incontinence of urine, no urinary investigations were possible and it was deemed unwise to pass a self-retaining catheter.

On the second day there was no sign of latent tetany but there was little change in the mental state. Further treatment was given (Fig. 5) and on the fourth day a slight hyperchloraemic acidosis was produced whilst the potassium level had returned to normal. On this day he was mentally alert and was able to give an accurate account of past events. By this time it was considered that his condition had improved sufficiently to undergo a gastro-enterostomy as an emergency procedure but ideally a partial gastrectomy seemed more desirable, particularly in view of the history of haemorrhage. For this reason a period of medical treatment was given in the hope that spasm or oedema at the pylorus would subside. This resulted in further vomiting with dehydration, hypochloraemia and hypokalaemia and clinical deterioration. After these abnormalities and the low haemoglobin level had been corrected by intravenous therapy, a gastro-enterostomy was performed as an emergency procedure. At laparotomy there was a severe cicatrical deformity of the pyloric ring but there was no oedema or evidence of spasm.

Three months later the patient was well and had no symptoms. The blood chemistry was normal except for a blood urea nitrogen of $44 \mathrm{mgm}$. per cent. The urea 
clearance test was 35 per cent. of average normal, but no abnormalities were found on routine urinalysis. As there was no hypertension or history of renal disease and the retinae were normal it was presumed that the renal impairment was a direct result of the pyloric stenosis and the accompanying alkalosis.

Five months after operation he developed melaena from an anastómotic ulcer and a partial gastrectomy was performed from which he made a satisfactory recovery.

\section{Conclusions}

The treatment of pyloric stenosis must of necessity bring physician, surgeon and biochemist together. It is imperative that the biochemical abnormalities should be treated first and as quickly as possible. This will prevent further deterioration in renal function by correcting the conditions likely to cause renal calcification and tubular degeneration. There are theoretical objections to treating, with saline alone, the sodium and chloride deficiencies which occur in the severe case. Firstly, the excess sodium that will be administered to correct the chloride depletion may result in the formation of an alkaline urine, which in turn may increase the chances of further deposition of calcium salts in the kidney. Secondly, if severe renal impairment is already present, the excretion of any sodium given in excess of requirements may be impaired, with subsequent hypernatraemia and delay in the correction of the alkalotic state. We believe that in all severe cases administration of chloride should always exceed that of sodium, a mixture of ammonium and sodium chlorides being eminently satisfactory.

In pyloric stenosis, potassium deficiency is common and is not confined to the extracellular fluid alone, for Mudge and Vislocky (1949) demonstrated an intracellular deficiency. In addition, excessive excretion of potassium may occur (see Case 2 above) during therapy. Potassium therapy must therefore be adequate to cover the daily excretion and the total body deficit.

Correction of the specific abnormalities present in the internal environment leads to a rapid improvement in the clinical state. It is at this point that the definitive treatment of the obstruction begins. Many of these patients are unsuitable for major surgical procedures because of the severe state of malnutrition. Ideally, a period of medical treatment should always be tried. If this is successful the question of surgery can be delayed until the nutritional state has been improved. If there is no apparent relief of the obstruction, surgery should not be withheld too long in the hope that spasm or oedema of the pyloric ring will subside, for the return of the biochemical abnormalities may be accompanied by a marked clinical deterioration. In our own small series of eight cases, seven required surgery after correction of the biochemical abnormalities, whilst the eighth responded to medical treatment, but he refused operation later.

\section{Acknowledgements}

Our thanks are due to Mr. D. B. Feather, Dr. H. G. Garland, Mr. A. J. C. Latchmore, Dr. A. Leese, Mr. H. S. Shucksmith and Prof. R. E. Tunbridge for permission to publish these cases; to Mr. F. J. N. Powell for the biochemical data on Case I and to Mr. J. Hainsworth and Miss C. E. Campbell, of the Department of Medical Photography, St. James' Hospital, Leeds, for the figures.

Fig. 5 is reproduced by kind permission of the editor, Recenti Progressi in Medicina.

Fig. 2 was kindly lent by Mr. L. N. Pyrah and Dr. G. M. Bonser.

\section{BIBLIOGRAPHY}

BARTLETT, R. M., BINGHAM, D. L. C., and PEDERSON, S. (1938), Surgery, 4, 614.

BOYCE, W. H., and VEST, S. A. (1952), F. Urol., 67, 169.

BROWN, G. E., EUSTERMAN, G. B., HARTMAN, H. R., and ROWNTREE, L. G. (1923), Arch. Int. Med., 32; 425.

COOKE, A. M. (1933), Quart. F. Med. N.S., 2, 539.

DEEDS, C. D. (1938), Proc. Mayo Clin., 13, 456.

GAMBLE, J. L. (1950), 'Extracellular Fluid,' Harvard Univ. Press, Cambridge, Massachusetts.

GOLDSCHMIDT, S., and DAYTON, A. B. (I919), Amer. F. Physiol., 48, 419, 433, 440, 450, 459.

HAWKINS, C. F., HARDY, T. L., and SAMPSON, H. H. (1951), Lancet, i, 318.

JONES, F. A. (1939), St. Bart's. Hosp. Rep., 72, 169.

KENNEDY, T. J., WINKLEY, J. H., and DUNNING, M. F. (1949), Amer. Ұ. Med., 6, 790 .

MCCANN, W. S. (1922), Proc. Soc. exp. Biol. and Med., 19, 393. MUDGE, G. H., and VISLOCKY, K. (1949), F. Clin. Invest., 28, 482 .

NAZZARI, A. (1904), Policlinico, Ir, 146.

PARSONS, F. M.' (1953), Recenti Progr. Med.

PARSONS, F. M., POWELL, F. J. N., and PYRAH, L. N. (1952), Lancet, ii, 599.

PYRAH L. N. (1949), Brit. F. Urol., 21, 27.

PYRAH, L. N., and BONSER, G. M., Personal communication.

ZEMAN, F. D., FRIEDMAN, W., and MANN, L. T. (1924), Proc. New York Path Soc., 24 4I.

Copies of Title Page and Index for Vol. 29 of The Postgraduate Medical Journal are now available on request. See page 173 for binding particulars. 